\title{
Evaluating the Effect of Using Mobile Phone Reminders on the Adherence to Children and Young Adults With Type 1 Diabetes Attending Outreach Appointments
}

\author{
Arsène Florent Hobabagabo ${ }^{1,2}$, Rex Wong ${ }^{2}$, Soha El-Halabi ${ }^{3}$, Edison Rwagasore ${ }^{4}$, Simon-Pierre Niyonsenga ${ }^{4}$, \\ Crispin Gishoma ${ }^{1,2}$, Etienne Uwingabire ${ }^{1}$, Alvera Mukamazimpaka ${ }^{1}$ \& Ziad El-Khatib ${ }^{5,6,7}$ \\ ${ }^{1}$ Rwanda Diabetes Association, Rwanda \\ ${ }^{2}$ University of Global Health Equity, Rwanda \\ ${ }^{3}$ Department of Learning, Informatics, Management and Ethics (LIME), Karolinska Institutet, Sweden \\ ${ }^{4}$ Rwanda Biomedical Center, Rwanda \\ ${ }^{5}$ Department of Global Health and Social Medicine, Harvard Medical School, USA \\ ${ }^{6}$ Department of Public Health Sciences, Karolinska Institutet, Sweden \\ ${ }^{7}$ World Health Programme, Université du Québec en Abitibi-Témiscamingue (UQAT), Canada \\ Correspondence: Arsène Florent Hobabagabo, Rwanda Diabetic Association, Rwanda. Tel: 250-785-755-769.
}

Received: January 12, 2019

Accepted: March 7, 2019

Online Published: March 11, 2019

doi:10.5430/jms.v10n2p60

URL: https://doi.org/10.5430/jms.v10n2p60

\begin{abstract}
Effective management of Type 1 Diabetes Mellitus (T1DM) requires that people living with the condition attend regular clinical visits. The Rwanda Diabetes Association (RDA) asks young T1DM patients to attend quarterly outreach visits, and prior to the visits, RDA issues reminders via local radio stations. However, adherence in attending clinical appointments has remained low.

Since Rwanda has a high mobile phone penetration rate, a pilot intervention study was conducted exploring the use of mobile phone call reminders and Short Message Service (SMS) messages to increase T1DM patients' attendance of RDA's quarterly outreach visits. The control group was exposed to only the regular radio broadcast, while the intervention group received reminder phone calls or SMS messages 72 hours prior to their appointments in addition to the regular radio broadcast.

The attendance rate was significantly different between the 14 control patients and 35 intervention patients, with $23.3 \%$ $(3 / 14)$ and $76.7 \%(27 / 35)$ attending visits, respectively $(\mathrm{P}=0.048)$.

The results suggest that using mHealth methods (phone call/SMS reminders) can be effective in improving health outcomes, improving the adherence of T1DM patients to follow-up visits with minimal added cost. The total cost was 0.37 USD per person, compared to potential 672.40 USD for each lost treatment, indicating the intervention is cost-effective in that it minimizes loss to follow up in resource-limited settings. Further research is needed to evaluate the feasibility of scaling up the pilot project and to understand whether improved attendance is sustained long-term.
\end{abstract}

Keywords: Type I Diabetes Mellitus, sub-Saharan Africa, loss to follow up, mHealth, mobile phone

\section{Introduction}

The emergence of non-communicable diseases (NCDs) is one of the biggest health challenges facing low- and middle-income countries (LMICs). The 2010 World Health Organization (WHO) Global Status Report showed that $63 \%$ of total deaths in the world in 2008 were due to NCDs, with $80 \%$ of these deaths occurring in LMICs (WHO, 2010). Of the many NCDs, Type 1 Diabetes Mellitus (T1DM) is a growing concern especially in LMICs (Majaliwa, Elusiyan, Adesiyun et al., 2008). The number of people affected by T1DM in sub-Saharan Africa (SSA) is expected to increase by $140 \%$ by 2040 (Ogurtsova et al., 2017). While the prevention and management of T1DM has significantly improved in high-income countries, there has been little to no improvement in SSA (Elling et.al. 2018). The International Diabetes Federation (IDF) estimated that about 39,100 (9 per 1,000) children below 15 years of age 
in SSA were diabetic in 2013 (IDF, 2015b). This number is most likely underestimated due to underdiagnosing and low awareness of the disease - about 9.5 million people in SSA were not aware of their conditions (IDF, 2015a).

Diabetes is a chronic condition that occurs when the body cannot produce enough insulin or use it appropriately (American Diabetes Association, 2017). As a result, glucose remains circulating in the bloodstream, leading to the development of disabling and life-threatening complications. T1DM is one of the three main types of diabetes and is caused by an autoimmune reaction of the body (Magliano, Zimmet, \& Shaw, 2015; American Diabetes Association, 2012). While there is no cure for T1DM, it can be managed; effective management requires a lifetime commitment from the people living with T1DM including regular follow-up, mostly quarterly but more frequent when needed (Ofori \& Unachukwu, 2014; Norris et al., 2002). Studies have shown that the regularity attendance of follow-up appointments is a strong predictor of a patient's ability to control his or her symptoms (Schectman, Schorling, \& Voss, 2008; American Diabetes Association, 2017; Windus et al., 2007; Gill et al., 2008; Benoit, Ji, Fleming, \& Philis-Tsimikas, 2004). However, despite the known importance of adherence to attending clinical appointments, published reports indicate low attendance rates, ranging from $29 \%$ to $72 \%$ (Amendezo, Walker, Karamuka et al., 2017; Marshall et al., 2015; Labhardt, Balo, Ndam, Manga, \& Stoll, 2011).

As Rwanda moves through an economic transition (Malunda, 2012; World Bank, 2016, 2017), the country has begun a transition from largely infectious disease burden to NCDs (Oni \& Unwin, 2015). Efforts by the Rwandan Ministry of Health $(\mathrm{MOH})$ to combat diabetes are supported by a number of civil society organizations, including the Rwanda Diabetes Association (RDA). The RDA makes quarterly outreach visits within the MOH's district hospitals to provide subsidized services to young T1DM patients (RDA, 2017a). Prior to the visits, the RDA announces the dates and names of health facilities that will be visited on local radio stations in order to invite young T1DM patients to attend. Attendance, however, has been low, with a 63\% clinic follow-up rate reported in 2016 (RDA, 2016). Studies have identified various factors leading patients to miss appointments, including economic issues, clinical status, administrative errors, and feeling ill (Griffin, 1998; Ngwenya, Van Zyl, \& Webb, 2009). Among these factors, forgetfulness is found to be one of the main reasons causing low adherence to clinical appointments - contributing to about 35\% of the missed clinic visits (Ngwenya, Van Zyl, \& Webb, 2009).

Among the different strategies that have been implemented to improve patient adherence to disease management, mHealth related interventions (i.e. using mobile devices, such as mobile phones) have been found effective in the management of chronic diseases, including diabetes, in high-income countries (de Jongh, Gurol-Urganci, Vodopivec-Jamsek, Car, \& Atun, 2012; WHO, 2011; Aranda-Jan, Mohutsiwa-Dibe, \& Loukanova, 2014). A systematic review of 14 studies found that mHealth have also been used to help diabetic patients with calculations related to insulin volume, food intake and physical activity (Hou, Carter, Hewitt, Francisa, \& Mayor, 2016).

In Rwanda, mobile phone coverage is close to $80 \%$ (RURA, 2016). This high mobile phone penetration rate presents numerous opportunities to implement mHealth interventions (Ngabo et al., 2012; Asiimwe-Kateera et al., 2015), including mHealth technology related to management of NCDs (Asiimwe-Kateera et al., 2015). This report summarizes a pilot study conducted by RDA, which tested the impact of mobile phone call reminders and Short Message Service (SMS) messages on attendance of T1DM patients of RDA's quarterly outreach visits. We hypothesized that phone calls and SMS messages reminders would increase the attendance of T1DM patients to their follow-up visits.

\section{Methods}

\subsection{Setting}

The pilot study was conducted in three rural provinces supported by RDA outreach activities: i) Rwinkwavu and Kirehe hospitals, in the Eastern province of Rwanda, ii) Mibilizi, a rural district hospital in the Western province and iii) Gitwe, a rural district in the Southern province. These sites have a similar number of T1DM patients registered (RDA, 2017b).

\subsection{Study Design and Sample}

This was a non-randomized longitudinal interventional study. The three sites were arbitrarily assigned into intervention and control groups. All registered T1DM patients in each site who fulfilled the following inclusion criteria were invited to participate in the study: i) enrolled in the RDA program; ii) attended baseline visit; iii) had a mobile phone in household (for patients of the interventions groups); iv) had a radio in household; v) was <26 years of age at the time of the study enrollment.

At the baseline visits (in November 2017), patient demographics and clinical information were collected. Follow-up visits took place in April 2018. The intervention took place 72 hours prior to the follow-up visits. 


\subsection{Control and Intervention}

The control group was exposed to the regular radio broadcast only, while the intervention group received phone calls or SMS messages to remind them of their appointments in addition to hearing the regular radio broadcast.

Approximately one-month prior the RDA's outreach visits, radio announcements were broadcasted as part of the usual care six times per week.

For the intervention group, phone calls/SMS messages were sent 72 hours prior to the appointment to allow enough time for the patients to prepare themselves for the appointment. In case a patient did not answer the phone calls, then the call was repeated up to three times at 12-hour intervals (i.e. 12, 24 and 36 hours) after the initial call. The mobile phone call reminders and SMS messages both consist the following message in Kinyarwanda (the local language) to ensure understanding:

"Rwanda Diabetes Association would like to inform all children and the youth, under the age of twenty-six, living with Type 1 Diabetes Mellitus in $<<$ name of the district $>>$ District that they will soon be meeting with RDA's caregivers to get tested and receive further information on diabetes free of charge on the $<<$ date $>>$ at $<<$ name of hospital >> District Hospital"

\subsection{Measures and Data Collection}

The key measure for this study was the percentage of T1DM patients who returned for a follow up visit. The number of patients who attended the last quarter clinical appointment in 2017 was used as denominator and the number who attended the first quarter clinical appointment in 2018 was used to calculate the adherence rate. Both the denominator and post-intervention attendance were collected from the health facility registration records.

Informed consent was collected at the baseline visit from patients of the intervention group after the purpose of the study was explained. Those who consented to participate were asked to provide a mobile phone number. Patient demographics including age, gender, marital status, economic status, level of education, travel distance and mode of transportation were recorded for both groups. Some clinical information was also collected via medical chart review, including family history, complications, history of missing at least one visit and history of complications. Two nurses from the RDA in charge of the outreach visits were responsible for calling the patients and sending the text messages. Two-day trainings were provided to them to ensure the messages they sent were consistent.

\subsection{Data Analysis Procedure}

Descriptive statistics were used to summarize patients' characteristics within the two groups as well as to look for associations with adherence. Fisher's Exact Test was used to compare discrete variables and Mann-Whitney U test for continuous variables to assess statistical differences. All statistical analyses were conducted using SPSS v.21 (Armonk, NY: IBM Corp. Released 2012), with P-value set at 0.05.

\section{Results}

The baseline data was collected in November 2017, with 14 patients enrolled from the control group hospital and 35 from the hospitals in the intervention group. The follow-up visit was in April 2018. The control and intervention group did not differ significantly in demographics or clinical characteristics (Table 1).

The attendance rate was significantly different between the control and intervention groups, with $23.3 \%$ attendance in the control group (radio announcement only) and $76.7 \%$ in the intervention group (Radio and phone calls/SMS reminders), with $\mathrm{p}=0.048$ (Table 3). None of the variables recorded, including age, marital status, education level, location of residence, transportation mode, transportation time, socio-economic level, number of years since diagnosed, history of default and history of complication were statistically significantly associated with attendance (all P>0.05) (Table 2).

Table 1. Comparison of characteristics of the intervention and control groups

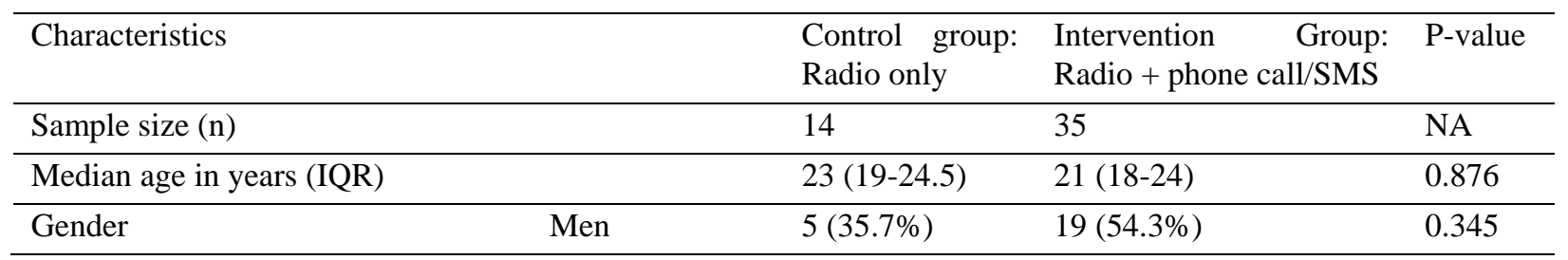




\begin{tabular}{lllll}
\hline & Women & $9(64.3 \%)$ & $16(45.7 \%)$ & 1.000 \\
\hline Marital status & Single & $14(100 \%)$ & $33(94.3 \%)$ & 0.755 \\
\hline Married & $0(0 \%)$ & $2(5.7 \%)$ & \\
\hline & Primary level & $7(50 \%)$ & $20(57.1 \%)$ & 0.193 \\
\hline Living area & Secondary level & $7(50 \%)$ & $15(42.9 \%)$ & \\
\hline & Rural & $12(85.7 \%)$ & $34(97.1 \%)$ & 0.089 \\
\hline Means of transport & Urban & $2(14.3 \%)$ & $1(2.9 \%)$ & \\
\hline & Walked & $10(71.4 \%)$ & $13(37.1 \%)$ & 0.766 \\
\hline Median minute for transport (IQR) & & $4(28.6 \%)$ & $21(60.0 \%)$ & 0.066 \\
\hline Socio-economic categories & Private car & $0(0 \%)$ & $1(2.9 \%)$ & \\
\hline & Poor & $120(60-157.5)$ & $120(60-180)$ & \\
\hline & Middle & $2(14.3 \%)$ & $12(34.3 \%)$ & \\
\hline Median years of the condition (IQR) & $5(2.75-7.25)$ & $3(1-5)$ & 0.142 & 0.244 \\
\hline History of defaulting & & $1(7.1 \%)$ & $9(25.7 \%)$ & \\
\hline History of Complications & & $1(7.1 \%)$ & $8(22.9 \%)$ & \\
\hline
\end{tabular}

Table 2. Factors contributing to attending follow-up appointments

\begin{tabular}{|c|c|c|c|c|}
\hline \multicolumn{2}{|l|}{ Variable } & Defaulted & Attended & P-value \\
\hline \multicolumn{2}{|l|}{ Sample (n) } & $6(12.2 \%)$ & $43(87.8 \%)$ & NA \\
\hline \multicolumn{2}{|l|}{ Median age in years (IQR) } & $24(20.8-24.8)$ & $21(18-24)$ & 0.316 \\
\hline \multirow[t]{2}{*}{ Intervention group } & Control: Radio only & $4(66.7 \%)$ & $10(23.3 \%)$ & $0.048^{*}$ \\
\hline & Intervention: Radio + calls/SMS & $2(33.3 \%)$ & $33(76.7 \%)$ & \\
\hline \multirow[t]{2}{*}{ Gender } & Men & $2(33.3 \%)$ & $22(51.2 \%)$ & 0.667 \\
\hline & Women & $4(66.7 \%)$ & $21(48.8 \%)$ & \\
\hline \multirow[t]{2}{*}{ Marital status } & Single & $6(100 \%)$ & $41(95.3 \%)$ & 0.768 \\
\hline & Married & $0(0 \%)$ & $2(4.7 \%)$ & \\
\hline \multirow[t]{2}{*}{ Level of education } & Primary level & $2(33.5 \%)$ & $25(58.1 \%)$ & 0.388 \\
\hline & Secondary level & $4(66.7 \%)$ & $18(41.9 \%)$ & \\
\hline \multirow[t]{2}{*}{ Living area } & Rural & $5(83.3 \%)$ & $41(95.3 \%)$ & 0.330 \\
\hline & Urban & $1(16.7 \%)$ & $2(4.7 \%)$ & \\
\hline \multirow[t]{3}{*}{ Means of transport } & Walked & $3(50.0 \%)$ & $20(2.3 \%)$ & 0.926 \\
\hline & Bus/motorcycle & $3(50.0 \%)$ & $22(51.2 \%)$ & \\
\hline & Private car & $0(0 \%)$ & $1(2.3 \%)$ & \\
\hline \multicolumn{2}{|c|}{ Median transport time in minutes (IQR) } & $90(60-135)$ & $120(60-180)$ & 0.355 \\
\hline \multirow[t]{3}{*}{ Socio-economic categories } & Poor & $2(33.3 \%)$ & $17(39.5 \%)$ & 0.948 \\
\hline & Middle & $2(33.3 \%)$ & $12(27.9 \%)$ & \\
\hline & Rich & $2(33.3 \%)$ & $14(32.6 \%)$ & \\
\hline \multicolumn{2}{|c|}{ Median of condition's duration in years (IQR) } & $5(5-6.5)$ & $3(1-6)$ & 0.129 \\
\hline \multicolumn{2}{|c|}{ History of defaulting } & $1(16.7 \%)$ & $9(20.9 \%)$ & 0.645 \\
\hline \multicolumn{2}{|l|}{ History of Complications } & $0(0 \%)$ & $9(20.9 \%)$ & 0.577 \\
\hline
\end{tabular}

* statistically significant at $\mathrm{P}=0.05$ 


\section{Discussion}

Effective management of T1DM requires regular follow-up visits. Through its standard use of radio announcements, RDA is not able to maximize attendance of follow-up visits. Phone calls and SMS reminders represent an opportunity to communicate with patients prior to visits and to increase their likelihood to attend them.

This pilot study compared the attendance of an intervention group exposed to phone calls and SMS reminders in addition to RDA's standard radio announcements to that of a control group only exposed to the radio announcements. The results found that the use of phone call/SMS reminders was associated with an increase in attendance relative to the control group, indicating that mHealth methods are effective in improving attendance to the quarterly clinical appointments for diabetic patients. Our pilot study results were similar to some previous published studies. A systematic review of published peer-reviewed articles on mHealth projects in Africa showed that pilot studies generally had positive results in improving patient attendance to follow-up consultations and adherence to their treatments (Aranda-Jan et al., 2014). Similar results were also found in Asia. In Cambodia, by contacting 109 patients who were referred for tuberculosis treatment, 97\% attended the treatment (Choun et al., 2017). Although that study was not conducted on diabetic patients, this report is consistent with our results and indicates that mHealth interventions can be effective in enhancing treatment adherence. Similarly, a comparable randomized controlled study in Malaysia showed that sending SMS reminders or phone calls to patients increased the attendance to primary healthcare consultations (Leong et al., 2006).

The success of this pilot relied on the simplicity and feasibility of the intervention. Phone calls and SMS messages are basic day-to-day events in our lives. In Rwanda, with its mobile phone penetration over 76\% (RURA, 2016), using mobile technology is a logical mode of intervention. The SMS messages and phone calls were conducted in Kinyarwanda. Using the local language in Rwanda facilitated patient understanding. The implementation was easy and required minimal additional training for callers.

It is important to note that the implementation of the mHealth intervention did pose an additional cost, including airtime to send SMS and make phone calls as well as the salary of the nurses involved in the follow-ups. The total cost, including the nurses' pro-rated wage, the price of the text messages and the phone calls was 12.93 USD, translating to 0.37 USD per person. However, this cost is contrasted with the cost of missing a session, which can waste 672.40 USD of the treatment previously provided to a patient. With such minimal cost, our intervention could be a cost-effective way to significantly improve attendance of clinic visits. In this study, we did not compare the impact of SMS versus phone call reminders on patient attendance, but this is an area for further research. Other similar studies have found SMS to be more cost-effective than phone call reminders (Leong et al., 2006; Perron et al., 2013). This is likely due to the uniformity of SMS: phone calls have variable durations, and callers have a tendency to deviate from the script depending on the interaction during the call. The average cost for each SMS text message was about 0.06 USD and for each phone call was 0.35 USD. Future studies should evaluate the effectiveness of SMS versus phone calls in order to provide information to determine the choice of the intervention, especially for resource-limited settings.

This was a pilot study; therefore, the sample size was small and limited the power of the study. Nevertheless, the results provide preliminary evidence of the effectiveness of this mHealth intervention. Because the study only evaluated the attendance of one clinical appointment, longer-term follow-up is needed.

One challenge the project faced was the irregular supply of electricity, especially in rural areas. In case of prolonged shortage of power, patients could have difficulty in re-charging their phones and thus receiving the announcement reminders. We sought to minimize the impact of this limitation by making repeated phone calls or sending messages if the first attempt failed. Other organizations should consider this factor when implementing mHealth interventions.

\section{Conclusion}

This study evaluated the impact of a mHealth intervention (i.e. phone calls and SMS reminders) on the follow-up visit attendance of T1DM patients enrolled in RDA care. The study found improved attendance in the intervention groups relative to the control group. Based on this, the use of mobile technology in the care of T1DM patients could help improve their adherence to follow-up visits with minimal added cost. Further studies are needed to plan for scale-up of the pilot and to follow-up on patients longer-term.

\section{Acknowledgement}

The authors would like to thank the staff of RDA for their dedication and commitment to the diabetic patients in Rwanda. We would also like to thank all patients who have participated in this study. 


\section{References}

Amendezo, E., Timothy, D. W., Karamuka, V., Robinson, B., Kavabushi, P., Ntirenganya, C., .. Umulisa, H. (2017). Effects of a lifestyle education program on glycemic control among patients with diabetes at Kigali University Hospital, Rwanda: A randomized controlled trial. Diabetes Research and Clinical Practice, 126, 129-137. http://doi.org/10.1016/j.diabres.2017.02.001

American Diabetes Association. (2017, January). Standards of Medical care in diabetes 2017. The Journal of Clinical and Applied Research and Education, 40, 1-142.

Aranda-Jan, C. B., Mohutsiwa-Dibe, N., \& Loukanova, S. (2014). Systematic review on what works, what does not work and why of implementation of mobile health (mHealth) projects in Africa. BMC Public Health, 14(1), 188. https://doi.org/10.1186/1471-2458-14-188

Asiimwe-Kateera, B., Condo, J., Ndagijimana, A., Kumar, S., Mukeshimana, M., Gaju, E., \& Kurth, A. (2015). Mobile Health Approaches to Non-Communicable Diseases in Rwanda. Rwanda Journal, 2(1), 89. https://doi.org/10.4314/rjhs.v2i1.13F

Benoit, S. R., Ji, M., Fleming, R., \& Philis-Tsimikas, A. (2004). Predictors of dropouts from a San Diego diabetes program: a case control study. Preventing Chronic Disease, l(4), A10.

Choun, K., Achanta, S., Naik, B., Tripathy, J. P., Thai, S., Lorent, N., \& Zachariah, R. (2017). Using mobile phones to ensure that referred tuberculosis patients reach their treatment facilities: A call that makes a difference. $B M C$ Health Services Research, 17(1), 1-7. https://doi.org/10.1186/s12913-017-2511-x

de Jongh, T., Gurol-Urganci, I., Vodopivec-Jamsek, V., Car, J., \& Atun, R. (2012). Mobile phone messaging for facilitating self-management of long-term illnesses (Review). Cochrane Database of Systematic Reviews, (12). https://doi.org/10.1002/14651858.CD007459.pub2

Elling, D., Surkan, P. J., Enayati, S., \& El-Khatib, Z. (2018, November 28). Sex differences and risk factors for diabetes mellitus - an international study from 193 countries. Global Health, 14(1), 118. https://doi.org/10.1186/s12992-018-0437-7

Gill, G. V., Price, C., Shandu, D., Dedicoat, M., \& Wilkinson, D. (2008). An effective system of nurse-led diabetes care in rural Africa. Diabetic Medicine, 25(5), 606-611. https://doi.org/10.1111/j.1464-5491.2008.02421.x

Griffin, S. J. (1998). Lost to follow-up: The problem of defaulters from diabetes clinics. Diabetic Medicine, 15(SUPPL

$3)$,

S14-24. https://doi.org/10.1002/(SICI)1096-9136(1998110)15:3+<S14::AID-DIA725>3.3.CO;2-9

Hou, C., Carter, B., Hewitt, J., Francisa, T., \& Mayor, S. (2016). Do mobile phone applications improve glycemic control (HbA1c) in the self-management of diabetes? A systematic review, meta-analysis, and GRADE of 14 randomized trials. Diabetes Care, 39(11), 2089-2095. http://doi.org/10.2337/dc16-0346

International Diabetes Federation (IDF). (2015a). IDF Diabetes Atlas 7th edition. International Diabetes Federation. Brussels: International Diabetes Federation.

International Diabetes Federation (IDF). (2015b). IDF Life for a Child Programme Annual Report 2015. Sidney.

Labhardt, N. D., Balo, J. R., Ndam, M., Manga, E., \& Stoll, B. (2011). Improved retention rates with low-cost interventions in hypertension and diabetes management in a rural African environment of nurse-led care: A cluster-randomised trial. Tropical Medicine and International Health, 16(10), 1276-1284. https://doi.org/10.1111/j.1365-3156.2011.02827.x

Leong, K. C., Chen, W. S., Leong, K. W., Mastura, I., Mimi, O., Sheikh, M. A., \& Teng, C. L. (2006). The use of text messaging to improve attendance in primary care: a randomized controlled trial. Family Practice, 23(6), 699-705. https://doi.org/10.1093/fampra/cml044

Magliano, D. J., Zimmet, P., \& Shaw, J. E. (2015). Classification of diabetes mellitus and other categories of glucose intolerance. International Textbook of Diabetes Mellitus (pp. 1-16). John Wiley \& Sons, Ltd. https://doi.org/10.1002/9781118387658.ch1

Majaliwa, E. S., Elusiyan, B. E. J., Adesiyun, O. O., Laigong, P., Adeniran, A. K., Kandi, C. M., \& Iughetti, L. (2008). Type 1 diabetes mellitus in the African population. Diabetes Care, 30(9), 255-259.

Malunda, D. (2012, March). Report for the African Centre for Economic Transformation (ACET) Rwanda: Case Study on Economic Transformation. Institute of Policy Analysis and Research - Rwanda (IPAR), 1-64. 
Marshall, S. L., Edidin, D. V, Arena, V. C., Becker, D. J., Bunker, C. H., Gishoma, C., \& Orchard, T. J. (2015). Glucose control in Rwandan youth with type 1 diabetes following establishment of systematic, HbA1c based, care and education. Diabetes Research and Clinical Practice, 107(1), 113-122. https://doi.org/10.1016/j.diabres.2014.09.045

Ngabo, F., Nguimfack, J., Nwaigwe, F., Mugeni, C., Muhoza, D., Wilson, D. R., \& Binagwaho, A. (2012). Designing and Implementing an Innovative SMS-based alert system (RapidSMS-MCH) to monitor pregnancy and reduce maternal and child deaths in Rwanda. The Pan African Medical Journal, 13, 31.

Ngwenya, B., Van Zyl, D., \& Webb, E. (2009). Factors influencing non-attendance of clinic appointments in diabetic patients at a Gauteng hospital in 2007 / 2008. Journal of Endocrinology, Metabolism and Diabetes of South Africa, 14(2), 106-110. https://doi.org/10.1080/22201009.2009.10872203

Norris, S. L., Nichols, P. J., Caspersen, C. J., Glasgow, R. E., Engelgau, M. M., Jack, L., \& McCulloch, D. (2002). Increasing diabetes self-management education in community settings: a systematic review (Structured abstract). American Journal of Preventive Medicine, 22(Supplement 4), 39-66. http://doi.org/10.1016/S0749-3797(02)00424-5

Ofori, S. N., \& Unachukwu, C. N. (2014). Holistic approach to prevention and management of type 2 diabetes mellitus in a family setting. Diabetes, Metabolic Syndrome and Obesity: Targets and Therapy, 7, 159-168. http://doi.org/10.2147/DMSO.S62320

Ogurtsova, K., da Rocha Fernandes, J. D., Huang, Y., Linnenkamp, U., Guariguata, L., Cho, N. H., \& Makaroff, L. E. (2017). IDF Diabetes Atlas: Global estimates for the prevalence of diabetes for 2015 and 2040. Diabetes Research and Clinical Practice, 128, 40-50. http://doi.org/10.1016/j.diabres.2017.03.024

Oni, T., \& Unwin, N. (2015). Why the communicable/non-communicable disease dichotomy is problematic for public health control strategies: Implications of multimorbidity for health systems in an era of health transition. International Health, 7(6), 390-399. https://doi.org/10.1093/inthealth/ihv040

Perron, N. J., Dao, M. D., Righini, N. C., Humair, J. P., Broers, B., Narring, F., Gaspoz, J. M. (2013). Text-messaging versus telephone reminders to reduce missed appointments in an academic primary care clinic: A randomized controlled trial. BMC Health Services Research, 13(1). http://doi.org/10.1186/1472-6963-13-125

Rwanda Diabetes Association (RDA). (2016). RDA/LFAC Report of Third Quarterly Visit 2016. Kigali.

Rwanda Diabetes Association (RDA). (2017a). Our Story | Rwanda Diabetes Association. Retrieved February 27, 2017, from http://rwandadiabetes.com/our-story/

Rwanda Diabetes Association (RDA). (2017b). RDA/LFAC Report of Second Quarterly Visit 2017.

Rwanda Utilities Regulatory Authority (RURA). (2016). Statistics and tariff information in telecommunication, media and postal service as of March 2016.

Schectman, J. M., Schorling, J. B., \& Voss, J. D. (2008). Appointment adherence and disparities in outcomes among patients with diabetes. Journal of General Internal Medicine, 23(10), 1685-1687. https://doi.org/10.1007/s11606-008-0747-1

Windus, D. W., Ladenson, J. H., Merrins, C. K., Seyoum, M., Windus, D., Morin, S., \& Goldfeder, J. (2007). Impact of a multidisciplinary intervention for diabetes in Eritrea. Clinical Chemistry, 53(11), 1954-1959. https://doi.org/10.1373/clinchem.2007.095067

World Bank. (2016). Urban population (\% of total) Data. Retrieved May 12, 2018, from https://data.worldbank.org/indicator/SP.RUR.TOTL.ZS

World Bank. (2017). World Development Indicators DataBank. Retrieved June 15, 2017, from http://databank.worldbank.org/data/reports.aspx? source=2\&type=metadata\&series=NY.GDP.MKTP.CD

World Health Organization. (2010). Global status report on non-communicable diseases 2010.

World Health Organization. (2011). mHealth: New horizons for health through mobile technologies. Observatory, 3(June), 66-71. Retrieved from http://www.webcitation.org/63mBxLED9 